\title{
7
}

\section{Faculty Development Through Student Learning Initiatives: Lessons Learned}

Nancy Simpson, Jean Layne,

Adalet Baris Gunersel, Blake Godkin, Jeff Froyd

Texas A\&M University

A project aimed at improving student learning while facilitating the professional development of faculty participants in the area of teaching has yiclded a rich collection of data. In addition to providing critical information about how faculty members think, the project has broadened our thinking regarding the link between student learning initiatives and faculty development. The project has also increased our understanding of the interests of faculty members who are not typically clients of faculty development centers and motivated thinking on how to serve the professional development goals of this group.

Tow do faculty members' beliefs and practices in the area of teaching and Ilearning change as a result of their involvement in a project intended to improve student learning and teaching? This question has captured our attention as faculty developers on the research team for Writing for Assessment and Learning in the Natural and Mathematical Sciences (WALS), as we seek to understand the professional development of faculty members as teachers. The process of answering this question has refocused our attention on motivations and prior knowledge of the faculty members with whom we work. This chapter describes our methodology, initial findings, and lessons learned from this investigation, and their impact on our work as faculty developers. We begin by describing the motivation and activities of the project and the methodology for interviews with faculty participants. We then present findings from the interviews and conclude with a description of how what we learned has influenced the direction and activities of the project. 


\section{Project Description}

\section{Motivation for WALS}

In 2003, a team of science faculty members and faculty developers at Texas A\&M University received National Science Foundation funding for Writing for Assessment and Learning in the Natural and Mathematical Sciences, a project that uses Calibrated Peer Review ${ }^{\mathrm{TM}}$ (http://cpr.molsci.ucla.edu/), to create and evaluate student writing assignments in biology, mathematics, and physics. WALS was designed to address three needs: the need for assessment tools that yield information about the kind of learning valued by mathematics and science faculty members, the need for faculty-driven inquiry into questions about learning and teaching, and the need for students to write in order to refine their communication and thinking specific to particular disciplines.

The need for assessment tools. Mathematics and science learning that emphasizes conceptual understanding and promotes critical thinking and communication skills is central to producing a scientifically literate workforce and citizenry. The way we assess learning is the most powerful signal that we send to students about what is important (Wiggins, 1990). Measures that give insight into student thinking are needed-both to communicate to students that it is their ability to think like scientists that is valued and to provide information for the improvement of teaching methods. And, since faculty members reasonably seek evidence that a change from more traditional teaching methods will lead to better student learning, lack of adequate assessment hinders the widespread adoption of inquiry-based, active-learning teaching methods (Guskey, 2002; Wright et al., 1998).

The need for faculty-driven inquiry. Adequate assessment methods and tools are necessary-but not sufficient-for the improvement of student learning. Devotion of faculty time and intellectual energy to careful analysis of assessment is also required. While there is a need for assessment methods that can show what students have learned, even more pressing is the need for faculty members to investigate questions about optimal conditions under which students acquire deep conceptual understanding and develop habits of disciplinary thinking. As Cross and Steadman (1996) write in the introduction to their book Classroom Research, "Just as students must be actively engaged in formulating their own learning questions and thinking critically about them, so teachers must be actively engaged in formulating their own questions about learning and the impact of their teaching upon it" (p. 2).

The need for students to write. Not only is it important for students to learn to write, but writing is, in itself, an effective learning tool. Well-crafted writing assignments promote active reading and critical thinking (Lowman, 
1996), and student writing gives a clearer picture of what students have learned than short answer or machine-scored multiple-choice exams (Elbow, 1997). Recognizing this, the university implemented writing-intensive course requirements, and WALS is motivated in part by the need to provide support for faculty members seeking to offer writing-intensive courses.

\section{WALS Activities}

Thirteen faculty members (four from mathematics, four from biology, and five from physics) participated in the project during 2003-2004, motivated both by their desire to have their students do more writing and by the provision of two weeks of summer support from the WALS grant. The initial activity was a two- and one-half-day workshop during which faculty learned to author and administer writing assignments using Calibrated Peer Review ${ }^{\mathrm{TM}}$ (CPR). CPR, a tool designed by a team of chemists from the University of California-Los Angeles with support from the National Science Foundation, requires significant faculty time in assignment authoring. However, because the assignments are peer graded and the whole process is computer managed, relatively little faculty time is needed in administration and grading. This makes it possible to implement writing assignments in large classes without adding significantly to grading time.

During the introductory workshop, faculty members met in three departmental teams to discuss the kinds of questions that would be appropriate for CPR assignments, and spent the majority of their time creating assignments that they would implement during either the fall or spring semester. Throughout the year, they met as a group and as departmental teams to share successes as well as to discuss the challenges involved with implementation. At the end of the academic year, they participated in an all-day retreat/workshop during which they analyzed samples of student writing to gain insight into the learning that the students were (or were not) able to demonstrate through their writing. The format of this analysis is described in a later section of this chapter.

\section{How Faculty Members Were Initially Thinking About Thinking and Learning}

Our evaluation of WALS addressed the question "How do faculty beliefs and practices change as result of their involvement with this project?" To provide a baseline from which to measure change, we interviewed faculty, using the stimulated recall method, then recorded, analyzed, and coded the interviews. This section describes the methodology and its implementation. 
The stimulated recall method was first introduced by Bloom (1956), who used the videotape or audiotape of a class period to help the interviewee (usually the teacher of the class) remember and report his or her thoughts. For the WALS project, we videotaped faculty participants during a regular class period. We then interviewed them, using segments of the videotape to stimulate their recollection of what was happening and what they were thinking during the class. We audiotaped, transcribed, and analyzed all the interviews for their content (Clark \& Peterson, 1986).

With stimulated recall, researchers can select interview segments in different ways. One approach is to watch the tape ahead of time, identify critical moments, and use them during the interview. We believed that using this approach would insert too much of our own thinking into the interview since we would be the ones deciding which incidents were important and which were not. Because the objective of these interviews was to obtain a picture of the current state of faculty thinking, we chose instead an approach that minimized the effect of our own beliefs and that could be kept consistent for all interviewees. At the beginning of each interview, the interviewer showed professors a few minutes of the beginning of the class to help them remember that specific class period. The interviewer then fast-forwarded to a two- to five-minute segment within each ten-minute interval. The segments were randomly selected by the interviewer unless the faculty member indicated a place on the tape where he or she wished to pause and make comments. After each of these segments the interviewer asked questions.

Since the purpose of the interview was to get the thoughts, beliefs, and practices of the professors, the interviewer used open-ended questions such as "What were you thinking at this moment?" and "What were you thinking about the students' understanding of the material?" The interviewer followed up with probing questions such as "Can you tell me more about that?" "How often does that happen?" "Why do you think that happened?" and "Why did you think that?" In order to better understand professors' pedagogical practices, the interviewer asked questions such as "How often do you use that strategy?" "How often do students ask questions?" or "What do you do when you encounter that problem?" In addition, after the initial three-minute segment, the interviewer asked the goals for that class period and at the end, the interviewer asked whether the goals had been accomplished.

We transcribed and coded the interviews. Rather than begin with a particular framework, we chose to allow the themes to emerge from the data (Strauss \& Corbin, 1998). We each read the first several transcripts together and observed recurring themes and categories of professor statements, keeping in mind our research question: "What are the current teaching/learning 
beliefs and practices of these professors?" To keep our work consistent through all the transcripts, we kept notes about what we meant by each category. After completing six transcripts we refined the categories and finished coding the interviews. The interviews are the primary source of data for the findings that are presented in the next section.

\section{Project Findings}

Four categories of comments emerged from our analysis: 1) pedagogical practices, 2) personal practical theories, 3 ) assumptions about students, and 4) pedagogical content knowledge. While a comprehensive discussion of what participants said is beyond the scope of this chapter, the following briefly describes each category to anchor the lessons learned that are presented in the final section of this chapter.

\section{*Pedagogical Practices}

We categorized participant descriptions of the methods they use to communicate content knowledge and to facilitate student learning as pedagogical practices, including descriptions of use of lecture, questioning, examples, and demonstrations. Faculty participants generally began by recalling what they were doing on the particular segment of videotape they had just viewed, then elaborating with descriptions of other strategies that they use in the classroom. Understanding how faculty describe their teaching practices at the outset of the project serves several purposes. First, while the ultimate goal of faculty development is improving student learning, it is not often easy to directly attribute increases in student learning to faculty development programs. What is possible, however, is to look for changes in teaching practices. This collection of faculty descriptions included in pedagogical practices gives us a baseline from which to identify change. Second, this category helps us identify what new strategies we might suggest to enhance current practice. Finally, since faculty members do not always find it easy to articulate their beliefs about teaching and learning, knowing how they teach allows us to infer beliefs that drive their practice. Many educational researchers suggest that faculty choose to teach in certain ways because of their beliefs about teaching and learning (Cothran et al., 2005). Ernest (1989, as cited in Cothran et al., 2005) suggests that beliefs impact what teachers select for content and how they deliver the content. Further, according to Grasha (1996), personal assumptions about teaching and learning "play an important role in how we design and implement a variety of classroom processes" and "help to guide 
and direct our actions in the classroom" (p. 101). The following interview excerpts illustrate some pedagogical practices.

This is the pulling-teeth stage now. It's like, "How can I get them to get the answer without me just telling it to them?... I was thinking "I don't want to just give them the answer, but what questions can I ask to draw the answer out of them?"

So, in the lecture, I have demonstrations... which I consider very important in introductory physics lectures... that's what physics is all about, I think.

There was a time many years ago when I believed that I could sort of read their expressions. And if I got a lot of blank stares, I slowed down, I gave more examples, I provided more explanation.... I'm having more difficulty these days,... I'm seeing more deadpan expressions. There seems to be less overt signals, at least that I recognize, which tell me confusion or comprehension. I don't know what I'm missing.

\section{: Personal Practical Theories}

While part of our understanding of faculty beliefs about teaching and learning is derived from their descriptions of how they teach, some faculty participants were explicit about what they believe about teaching and learning. We categorized these statements as personal practical theories. Such theories are "formed through experience and reflection, include images of teaching and learning, the roles of teachers and students, and the purposes of and methods for content instruction" (Gess-Newsome, Southerland, Johnston, \& Woodbury, 2003, p. 758). They "both shape and constrain teachers' interactions with reform" (Gess-Newsome et al., 2003, p. 758), forming the filter through which new information is evaluated, internalized, and acted upon.

The identification of personal practical theories is critical to projects like WALS for several reasons. First, faculty members may not have articulated these theories often-or ever. Leaving these theories invisible makes them more difficult to identify and track for the purpose of professional development (Sanders \& McCutcheon, 1986). Second, by identifying personal practical theories and examining them in light of the learning literature, we begin to get an idea of what the faculty participants already know about the learning process that is supported-or not-by cognitive science. Third, we gain insight into how faculty members are filtering and processing their experiences with students as well as their experiences in informal/formal faculty de- 
velopment opportunities. We give a few examples of these theories in the next paragraph.

When speaking of the language barrier between him and the students, one faculty participant commented, "Repetition. That's the cure for a lot of things. Do things over and over and over again, with different approaches, maybe with different words that mean the same things." About encouraging his students to ask questions, a participant said, "I can tell by the questions I'm getting where they are, what they're understanding, what they're missing." Another participant commented that in order to have an effective class, "you've got to engage students early on."

\section{:Assumptions About Students}

In addition to descriptions of teaching practices and of beliefs about teaching and learning, faculty participants shared their assumptions about student ability and motivation and about their expectations of or about students. We included these statements in the category assumptions about students. All educators meet their learners with certain beliefs about teaching and learning (Leamnson, 1999), and these beliefs are affected and modified by beliefs about the learners themselves. Because of this, we believe it is important to understand the beliefs, expectations, and assumptions faculty have about students. We know that the potential impact of these assumptions is significant. Rosenthal and Jacobson's (1968, as cited in Bamburg, 1994) "Pygmalion in the Classroom" research began a series of research projects regarding the effect of teacher expectations on students. Douglas (1964) and Mackler (1969) found that

Teachers' expectations about student achievement can be affected by factors having little or nothing to do with his or her ability, and yet these expectations can determine the level of achievement by confining learning opportunities to those available in one's track. (as qtd. in Bamburg, 1994, p. 7)

Tauber (1998) describes the Pygmalion Effect as "the idea that one's expectations about a person can eventually lead that person to behave and achieve in ways to confirm those expectations" (p. 3). It is possible that faculty participants' beliefs about their students affect the way in which they communicate with their students and artificially limit their choice of pedagogies.

We want to identify recurring assumptions of faculty participants and observe how these assumptions impact their teaching and evolve through the WALS experience. Does involvement in a project such as WALS lead faculty 
participants to question their assumptions or to inquire systematically about the underlying causes of student behavior? Our interviews have given us not only a baseline from which to gauge growth, but also a point of departure for motivating faculty classroom research. For example, one faculty member's comment suggested a testable hypothesis for a scholarly investigation:

Typically - I may be a little cynical - I anticipate that most students haven't had to think much in math classes before. Coming into my freshman math class, coming out of high school, I expect them not to think much about what they had done. So it's kind of a new experience for them.

Other participants communicated beliefs about student fragility and shyness or about their study habits. Again, these could be tested in order to affirm or disprove an assumption about students.

I think that students are a lot more fragile than they should be. And most of them don't enjoy arguing and give and take.

They tend to be, on the whole, somewhat of a quiet class. Sometimes I think it's because they aren't really sure of what's going on, or what I'm trying to get at, or something like that.

I get a lot more questions when homework is due. The reason is, of course, they usually do the homework the night before it's due. And they don't look at the course except when homework is due.

\section{Pedagogical Content Knowledge}

The final category that emerged from our analysis is pedagogical content knowledge. Shulman (1987) uses this term to describe the knowledge that faculty members need about the teaching of their discipline. Manouchehri (1996) describes pedagogical content knowledge as "how to represent specific topics or issues in ways that are appropriate to the diverse abilities and interests of learners" (p. 7). Bransford, Brown, and Cocking (2000) observe that

Expert teachers know the structure of their disciplines, and this knowledge provides them with cognitive roadmaps that guide the assignments they give students, the assessments they use to gauge students' progress, and the questions they ask in the give and take of classroom life. (p. 155)

While only a few of the faculty participants made statements that could be identified as pedagogical content knowledge, we believe that is important 
to identify and build on even the beginning of this kind of expertise in teaching. For example, one building block for pedagogical content knowledge is the recognition that particular concepts in the disciplines are difficult for students to grasp, and several of our professors made statements in this regard. For example, a physics professor observed,

... the class that we taped... is the hardest class of the entire semester in terms of comprehension ... it's because we're talking about internal rotational motion which is just a harder concept to grasp for them than translational motion. People are familiar with that because they drive the car, they walk, and the concepts of that type of motion are much easier to grasp for students than this internal rotational motion. It's also complicated because of the mathematical language that we use for describing it; you know the different parameters are not the parameters that people use in every day life.... People, I guess, have a much easier approach to something like velocity, because they are seeing it on their dashboard in the car all the time.

Pace and Middendorf (2004) provide a faculty development model that builds on this kind of knowledge in their work on "decoding the disciplines," and these initial interviews indicate that this model could be a productive approach with faculty involved in WALS.

Understanding what college faculty know-and how they know itabout the teaching of their discipline is important for faculty developers. Faculty often do not recognize that the insights gained from years of experience constitute a particular kind of expertise, and therefore they do not see it as something worth sharing with others. But, while the experiences of individual faculty members may not lead to disciplinary teaching theory, the combined experiences of many faculty could in fact lead to significant understanding about how to facilitate learning in a particular discipline. Faculty developers are ideally situated to hear these stories and to look for the patterns and connections that advance understanding of teaching and learning in that discipline.

\section{Lessons Learned and Future Work}

We turn now to a discussion of what we learned from this analysis and how it is informing our continued work. As previously stated, faculty members who decided to become involved in this project were motivated primarily by their desire to include more writing assignments in their courses and by the 
incentive of two weeks of summer salary. In this regard, they were unlike most of the faculty with whom we have worked in the past: They were not primarily motivated by a desire to improve their teaching or to engage in scholarly inquiry about their students' learning. While we knew this, we were not prepared for the challenges we encountered throughout the year as we attempted to engage these faculty members in discussion of articles and book chapters from the learning literature. In contrast to other groups of faculty who had found this material both interesting and useful, WALS faculty participants did not. Reading the transcripts of the stimulated recall interviews with participating faculty members helped us understand why this was the case. Our interviews gave us a better understanding of the knowledge, beliefs, values, and questions of faculty participants as "learners," and provided insights into how we might better promote their growth as scholars of learning and teaching. Specifically, we learned that faculty members are highly motivated by the content of their courses and that they are unsure whether their students are learning what they hope or expect them to learn. In the paragraphs that follow, we elaborate on these two points and describe the steps the research team has taken or will take in response.

First, we recognized that participating faculty members are passionate about their respective disciplines. Whether mathematics, physics, or biology, they love the concepts and thinking processes of their field and believe strongly that it is important for students to learn these disciplines. When asked about learning goals, they almost always described content and concepts. The interview transcripts were filled with enthusiastic descriptions of the substance of what they were teaching.

We built on this knowledge of our audience to develop the agenda for the retreat at the end of 2003-2004 where we introduced Anderson and Krathwohl's (2001) revision of Bloom's taxonomy. Specifically, since we were by this time well aware that it was "knowledge of critical content in the discipline" that was of primary value to participating faculty members, we developed the workshop around the "knowledge dimension" (p. 46). After describing factual knowledge, conceptual knowledge, procedural knowledge, and metacognitive knowledge, we asked the faculty participants to consider one of their CPR assignments and write down what knowledge in each category would be required for student success on the assignment. Participants then worked in disciplinary teams to analyze sample student writing and look for evidence of each type of knowledge. The level of faculty engagement with this exercise indicated that this particular analytic tool was a useful one. The template for this analysis is shown in Table 7.1. 
TABLE 7.1

The WALS Faculty's Template for Analyzing Student Writing

\begin{tabular}{|l|l|l|l|}
\hline & $\begin{array}{l}\text { Expectations (What did } \\
\text { students need to know in } \\
\text { order to be successful?) }\end{array}$ & $\begin{array}{l}\text { Evidence Exhibited } \\
\text { (What did students } \\
\text { know and what is the } \\
\text { evidence?) }\end{array}$ & $\begin{array}{l}\text { Evidence Missing or } \\
\text { Erroneous (What did } \\
\text { students not know and } \\
\text { what is the evidence?) }\end{array}$ \\
\hline $\begin{array}{l}\text { Factual } \\
\text { Knowledge }\end{array}$ & & & \\
\hline $\begin{array}{l}\text { Conceptual } \\
\text { Knowledge }\end{array}$ & & & \\
\hline $\begin{array}{l}\text { Procedural } \\
\text { Knowledge }\end{array}$ & & & \\
\hline $\begin{array}{l}\text { Metacognitive } \\
\text { Knowledge }\end{array}$ & & & \\
\hline
\end{tabular}

Note. Based on Anderson and Krathwohl (2001).

Second, while participating faculty were highly motivated to have their students "get" the content, they frequently expressed uncertainty that their students were learning-or if they are not learning, why not. Such uncertainty can either interfere with improvement of teaching and learning practices (by leaving faculty with a sense of discouragement regarding student learning outcomes) or be a catalyst for that improvement (by presenting questions worthy of investigation). Teaching is a complex activity that "involves more than simply behavior but thoughts, interpretations, choices, values, and commitments as well" (Sanders \& McCutcheon, 1986, p. 51). Lack of certainty about student understanding can lead to efforts to gain insight into the difficulties students may be having with the concepts, and we wanted to support these efforts.

The uncertainty about whether students were "getting it" pointed to the importance of analyzing student outcomes using CPR data; that is, we needed to provide participating faculty members with concrete data from which to make their conclusions about student learning. During summer and fall 2005, we began this kind of analysis, using data from the classes of two WALS professors. In one case, the outcomes were encouraging, showing increases in student ability to write about the content of the course. In the other case, the outcomes were, on the surface, discouraging. The students did not improve in their ability to write in the language of the particular discipline involved. 
But what appears to be bad news is, in fact, a catalyst for more careful investigation of what it is that makes this kind of writing so difficult for students. A particularly challenging element of teaching is that faculty members, who are longtime "expert" learners in their disciplines, may have forgotten what "novices" most need in order to make learning advances in the discipline. A next step is to work through the steps of the "decoding the disciplines" model (Pace \& Middendorf, 2004) with not only the particular professor involved, but also the others in the project. We believe that this will lead to beneficial redesign or refinement of the CPR assignments and to more satisfactory student performance.

From a learning standpoint, one of the benefits of both the campus commitment to writing intensive courses and our work with CPR is the explicit linkage of the writing process to the learning process. Students' efforts to articulate their disciplinary thinking confronts both students and faculty members with tangible evidence of confusion, misconceptions, lack of clarity, and so on. And it gives faculty greater insight into what is right as well as wrong with student conceptualizations. Our next step is to continue the quantitative and qualitative analysis of student outcomes using data from CPR in order to capitalize on the writing of the students.

Our experience with this project has given us fresh appreciation for the importance of understanding the conceptions of learning and teaching that faculty bring to faculty development opportunities, in particular to those offered in connection with student learning initiatives. The stimulated recall method is time intensive, but it yielded a wealth of information and insight into the thinking of faculty participants about a variety of issues related to learning and teaching. We encourage any faculty development unit looking to gain a richer understanding of the population they serve to utilize this methodology and to compare data with those from our project and other campuses.

\section{Note}

This material is based on work supported by the National Science Foundation under grant number DUE-0243209. 


\section{References}

Anderson, L.W., \& Krathwohl, D. R. (Eds.). (2001). A taxonomy for learning, teaching, and assessing: A revision of Bloom's taxonomy of educational objectives. New York, NY: Longman.

Bamburg, J. D. (1994). Raising expectations to improve student learning. Naperville, IL: North Central Regional Educational Laboratory.

Bloom, B. S. (Ed.). (1956). Taxonomy of educational objectives, handbook 1: Cognitive domain. New York, NY: Longman.

Bransford, J. D., Brown, A. L., \& Cocking, R. R. (Eds.). (2000). How people learn: Brain, mind, experience, and school (Expanded ed.). Washington, DC: National Academy Press.

Clark, C. M., \& Peterson, P. L. (1986). Teachers' thought processes. In M. C. Wittrock (Ed.), Handbook of research on teaching (3rd ed., pp. 255-296.). New York, NY: Macmillan.

Cothran, D. J., Kulinna, P. H., Banville, D., Choi, E., Amade-Escot, C., MacPhail, A., et al. (2005, June). A cross-cultural investigation of the use of teaching styles. Research Quarterly for Exercise and Sport, 76(2), 193-201.

Cross, K. P., \& Steadman, M. H. (1996). Classroom research: Implementing the scholarship of teaching. San Francisco, CA: Jossey-Bass.

Elbow, P. (1997). High stakes and low stakes in assigning and responding to writing. In M. D. Sorcinelli \& P. Elbow (Eds.), New directions for teaching and learning: No. 69. Writing to learn: Strategies for assigning and responding to writing across the disciplines (pp. 5-13). San Francisco, CA: Jossey-Bass.

Gess-Newsome, J., Southerland, S. A., Johnston, A., \& Woodbury, S. (2003, Fall). Educational reform, personal practical theories, and dissatisfaction: The anatomy of change in college science teaching. American Educational Research Journal, $40(3), 731-767$.

Grasha, A. F. (1996). Teaching with style: A practical guide to enhancing learning by undcrstanding teaching and learning styles. Pittsburgh, PA: Alliance.

Guskey, T. R. (2002, August). Professional development and teacher change. Teachers and Teaching: Theory and Practice, 8(3), 381-391.

Leamnson, R. (1999). Thinking about teaching and learning: Developing habits of learning with first year college and university students. Sterling, VA: Stylus. 
Lowman, J. (1996). Assignments that promote and integrate learning. In R. J. Menges, M. Weimer, \& Associates, Teaching on solid ground: Using scholarship to improve practice (pp. 203-232). San Francisco, CA: Jossey-Bass.

Manouchehri, A. (1996, October). Theory and practice: Implications for mathematics teacher education programs. Paper presented at the annual forum of the Association of Independent Liberal Arts Colleges for Teacher Education, Atlanta, GA.

Pace, D., \& Middendorf, J. (Eds.). (2004). New directions for teaching and learning: No. 98. Decoding the disciplines: Helping students learn disciplinary ways of thinking. San Francisco, CA: Jossey-Bass.

Sanders, D. P., \& McCutcheon, G. (1986, Fall). The development of practical theories of teaching. Journal of Curriculum and Supervision, 2(1), 40-67.

Shulman, L. S. (1987, Spring). Knowledge and teaching: Foundations of new reform. Harvard Educational Review, 57(1), 1-21.

Strauss, A., \& Corbin, J. (1998). Basics of qualitative research: Techniques and procedures for developing grounded theory (2nd ed.). Thousand Oaks, CA: Sage.

Tauber, R.T. (1998). Good or bad, what teachers expect from students they generally get! Washington, DC: ERIC Clearinghouse on Teaching and Teacher Education. (ERIC Document Reproduction Service No. ED426985)

Wiggins, G. (1990). The truth may make you feel free, but the test may keep you imprisoned: Toward assessment worthy of the liberal arts. AAHE Assessment Forum, 17-31.

Wright, J. C., Millar, S. B., Koscuik, S. A., Penberthy, D. L., Williams, P. H., \& Wampold, B. E. (1998, August). A novel strategy for assessing the effects of curriculum reform on student competence. Journal of Chemical Education, 75(8), 986-992. 